\title{
A note on earthquake-induced liquefaction
}

\author{
D. V. MORRIS (1983). Géotechnique 33, No. 4, 451-454
}

\section{Professor H. Bolton Seed, University of Califor- nia, Berkeley}

$\mathrm{Mr}$ Morris presents an interesting point of view on the development of design procedures to evaluate the liquefaction potential of soil deposits. It is clear, however, that he is not well informed about developments in this field during the past ten years or so-either as published in geotechnical engineering journals or as applied in engineering practice.

I shall discuss only his observations regarding what he describes as the Berkeley method for 'analysing' the liquefaction potential of soil deposits, which, he states, has 'concentrated on detailed computation of the passage of earthquake stress waves through the soil, followed by tests on soil samples to simulate the effects of the earthquake stresses'. In fact, as presented at Berkeley for the past ten years or more, the method involves

(a) the acquisition of a comprehensive background concerning field case histories of soil liquefaction during earthquakes and all proposed methods for evaluating the liquefaction potential of soil deposits

(b) the development and use of methods for evaluating the liquefaction potential based on field observations and case studies

(c) the conduct of laboratory studies on soil samples to throw light on the physical mechanisms by which liquefaction occurs under idealized conditions in the laboratory and to evaluate the possible effects of earthquake shaking on representative samples taken from the field

(d) the conduct of analytical studies to explore the mechanisms leading to the generation and dissipation of pore pressures in idealized models of soil deposits, including where appropriate consideration of soil softening and surface layer isolation

$(e)$ the development of simplified procedures for evaluating the liquefaction potential in practice, based on a knowledge of all aspects of the problem listed but with special emphasis on the use of engineering judgement based on field performance data: where analysis procedures are used they are checked against field performance data for applicability.

This is hardly a simple comparison of computed induced stresses with the results of laboratory tests as Mr Morris implies. Such a simple comparison was proposed, it is true, in 1970 at a time when there were virtually no field data available and laboratory testing and analysis procedures were in their infancy. It was at that time clearly described as a simplified method of liquefaction evaluation. Procedures and understanding have developed considerably since then, as most observers of the liquefaction field fully appreciate, and no serious student of soil liquefaction would recognize the Berkeley method as involving, for natural deposits, simply the determination of 'the magnitude of the earthquake bedrock parameters, evaluating elastic constants of the in situ soil, attempting to represent the predicted stress history by an equivalent number of cycles, measuring the in situ density of sands, and then attempting to prepare cyclic triaxial test specimens at this density'.

The Berkeley method which I have outlined here has long superseded the simplified approach which $\mathrm{Mr}$ Morris describes. Field case studies are now plentifully available and far more sophisticated analytical studies can now be performed. Thus analyses can now be routinely made, where it is appropriate, to study the generation and dissipation of porewater pressures during earthquake shaking, giving consideration to the non-linear stress-strain properties of the soil, the progressive changes in soil properties as pore pressures develop, the damping of motions in overlying layers as underlying layers liquefy or lose strength, changes in soil properties as liquefaction is approached etc.-in fact all the features which Mr Morris feels are the 'flaw of the Berkeley method'. Such studies have shown that this aspect of the 'flaw' can change the results of a liquefaction analysis, by about 5$15 \%$, hardly a 'serious error' compared with those which may be introduced by such other factors as the effects of sample disturbance (10$300 \%)$, soil ageing $(25-100 \%)$, the method of sample preparation $(0-100 \%)$ etc. It is the recognition of the potential effects of these other 


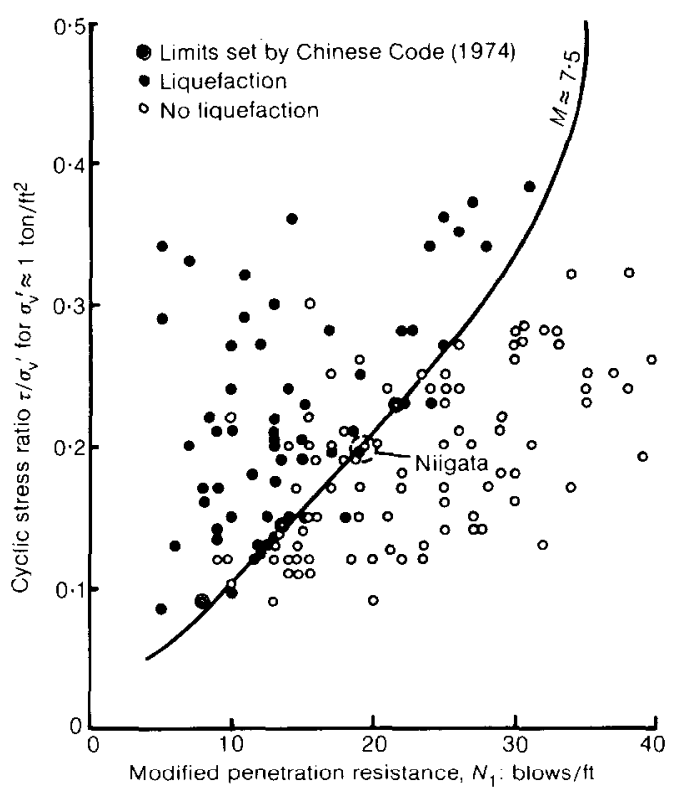

Fig. 1. Correlation between field liquefaction behaviour of sands under level ground conditions and standard penetration resistance.

factors far more than the dccoupling of stress analyses and laboratory test procedures which is essential to a fundamental understanding of soil liquefaction in the field. The Berkeley method involves the development and use of sophisticated analyses whenever it is appropriate, but we recommend that they be used only to develop insight into the mechanics of the problem and not for the direct solution of practical problems.

For solving practical problems, the Berkeley method advocates, wherever possible, the use of simple or empirical approaches based on field case studies. Contrary to Mr Morris' belief, such data are not very limited for liquefaction under level ground conditions, unless it is considered that the evaluation of over 150 sites in the USA, Japan, China, Argentina and Guatemala are an inadequate field data base. The available correlation between soil liquefaction resistance and the penetration resistance of sands, based on field studies, is shown in Fig. 1 (Seed \& Idriss, 1981). Most people engaged in soil liquefaction evaluations have known of the availability of such a data base for several years and have taken advantage of its availability for the evaluation of practical problems. Nevertheless, judgement is still an essential part of any reliable method and this involves many aspects of the problem, including keeping abreast of recent developments to provide a sound basis for design decisions.

\section{REFERENCE}

Seed, H. B. \& Idriss, I. M. (1981). Evaluation of liquefaction potential of sand deposits based on obscrvations of performance in previous carthquakes. In In situ testing to evaluate liquefaction susceptibility, Proc. Am. Soc. Civ. Engrs Natl Conv., St Louis, Missouri, 26-31 October, Preprint 81-544.

Professor A. Anandarajah, South Dakota School of Mines and Technology, and Professor $\mathbf{K}$. Arulanandan, University of California, Davis

The Technical Note raises many important questions related to earthquake-induced liquefaction of sand deposits. The Author attempts to demonstrate that the liquefaction phenomenon is fundamentally intractable analytically and suggests that the only way of developing reliable design procedures is by using centrifuge modelling, calibrated wherever possible against measured full-scale results. In the pore pressure generation-dissipation analysis proposed by the Berkeley school (incorporated in the computer program GADFLEA (Booker, Rahman \& Seed, 1976)), dynamic stressing is assumed to take place, as the Author points out, independently from soil softening. However, the variation in compressibility resulting from excess pore pressure build-up is considered in the analysis. Martin \& Seed (1979) developed an effective stress method in which two computer programs (MASH and APPOLLO) are coupled together iteratively to obtain consistent predictions for dynamic response and excess pore pressure. It is assumed in APPOLLO that, following any initial liquefaction, the soil compressibility remains constant at the maximum value achieved when liquefaction is initiated. An independent effective stress method of liquefaction analysis has been proposed by Martin, Finn \& Seed (incorporated in the computer program DESRA (Finn, 1981)). Attempts have recently been made to evaluate the significance of the assumptions built in this analysis in the final results of liquefaction predictions. The recent centrifuge model studies (Arulanandan, Anandarajah \& Abghari, 1983; Whitman, Lambe \& Akiyama, 1982) have indicated that the liquefaction behaviour of sand deposits predicted by the Berkeley school method and the MartinSeed method compared reasonably well with the centrifugal model behaviour. Further, G. R. Martin (Ertec Western Inc) has noted that the liquefaction behaviour predicted by DESRA and GADFLEA compared reasonably well with 
each other. Thus the assumptions built into these methods do not introduce significant errors in the final results.

Morcover, we wish to point out that many of the difficulties inherent in analytical methods are present also in centrifuge modelling. It is known that the liquefaction behaviour of sands depends on many factors such as cementation, structure, degree of previous seismic history etc., which cannot be incorporated either in analytical methods or centrifuge modelling unless these in situ characteristics can be quantified. There is no method available at present for the determination of these in situ conditions, although nondestructive in situ techniques such as electrical methods (Anandarajah, Arulanandan, Dafalias \& Herrmann, 1983; Arulanandan, Arulmoli \& Dafalias, 1982) are promising. The field behaviour would be further complicated by the presence of heterogeneitics such as loose pockets. Even if these in situ conditions can be determined, we wonder whether it would ever be possible to recreate these conditions in a centrifuge model. Added to these are the difficulties of simulating field boundary and loading conditions in the centrifuge model. We believe that the centrifuge model technique is very powerful in verifying theories and studying various phenomena associated with the behaviour of structures but cannot be used at present for accurate prototype predictions. In summary, the analytical methods using in situ soil properties are still the only reasonable means of predicting the liquefaction behaviour of field soils. The validity of analytical methods should be verified, however, and this may be done by centrifuge modelling, large-scale modelling and field observations. The shortcomings in the analytical procedures discussed here can be overcome by using accurate stress-strain models.

\section{REFERENCES}

Anandarajah, A., Arulanandan, K., Dafalias, Y. F. \& Herrmann, L. R. (1983). In situ determination of stress-strain relationship of clays. Int. Symp. Constitutive Laws for Engineering Materials: Theory and Application, Tucson, Arizona, 10-14 January.

Arulanandan, K., Anandarajah, A. \& Abghari, A. (1983). Centrifuge modeling of liquefaction susceptibility. J. Geotech. Engng Div. Am. Soc. Civ. Engrs 109, No. 3.

Arulanandan, K., Arulmoli, K. \& Dafalias, Y. R. (1982). In situ prediction of dynamic pore pressure in sand deposits. Int. Symp. Numerical Models in Geomechanics, Zurich, 13-17 September.

Booker, J. R., Rahman, M. S. \& Seed, H. B. (1976). GADFLEA-a computer program for the analysis of pore pressure generation and dissipation during cyclic or earthquake loading. EERC Report No. EERC 76-24, University of California, Berkeley.

Finn, W. D. F. (1981). Liquefaction potential: development since 1976. Proc. Recent Advances in Geotechnical Earthquake Engineering and Soil Dynamics, St Louis, Missouri, 26 April-3 May.

Martin, P. P. \& Seed, H. B. (1979). Simplified procedure for effective stress analysis of ground rcsponse. J. Geotech. Engng Div. Am. Soc. Civ. Engrs 105, GT6, 739-758.

Whitman, R. V., Lambe, P. C. \& Akiyama, J. (1982). Consolidation during dynamic tests on a centrifuge. Physical Modeling of Soil Dynamics Problems, Proc. Am. Soc. Civ. Engrs Natl Conv., Las Vegas, Nevada, 2630 April, Preprint 82-063. 